\title{
Biofilm forming capacity and antibiotic susceptibility of Staphylococcus spp. with the icaA/icaD/bap genotype isolated from ocular surface of patients with diabetes
}

\section{Sertaç Argun Kıvanç ${ }^{1}$, Gizem Arık², Berna Akova-Budak ${ }^{1}$, Merih Kivanç $^{2}$}

1. Uludag University, School of Medicine, Department of Ophthalmology, Görükle,Bursa/Turkey 2. Anadolu University, Faculty of Science, Department of Microbiology, Eskişehir/Turkey
Date Received: 20-March-2017 Revision Received: 08-Jan-2018 Date Accepted: 15-Jan-2018

Correspondence: Merih Kivanç, (mkivanc@anadolu.edu.tr)

https://dx.doi.org/10.4314/mmj.v30i4.6

\begin{abstract}
Introduction
Abstract

Bacterial biofilm is an exopolysaccharide matrix that is produced by bacteria while they adhere on abiotic or biotic surfaces. The bacteria living in this matrix are more resistant to antibiotics than planctonic bacteria. The biofilm formation property of the bacteria is determined by genes; and this is related to virulence of the microorganism. In ophthalmology, biofilms form especially on abiotic surfaces such as silicon tubes, contact lenses, intraocular lenses etc.

Aim

Our aim was to investigate genotypic and phenotypic structures of biofilms that are produced by Staphylococcus spp., which was obtained from the eyes of diabetic patients and determine the effect on antibiotic susceptibility.

Methods

The study group was comprised with 83 isolates from diabetic patients and 21 isolates from non-diabetic patients. Presumptive isolates were detected and confirmed by a microbial identification system VITEK II. Automated EcoRI Ribotyping was performed. Biofilm production was detected by Congo Red Agar Plate and Microtiter Plate Assay. Disc diffusion method was used for determination of antibiotic susceptibility of isolates.

Results

Out of the 83 isolates from diabetic patients, 25 were weakly (30\%), 20 were moderately (24\%), and 25 were strongly ( $30 \%$ ) biofilm positive. Seven isolates of S. aureus, 11 isolates of S.epidermidis, 2 isolates of S. warneri, 3 isolates of S.hominis, and 2 isolates of S.lugdunensis were identified as strong biofilm producers. Out of the 83 Staphylococcus isolates, 37 were cefuroxime, 18 ciprofloxacin, 11 vancomycin, 12 gatifloxacin, and 18 moxifloxacin resistant. In total, 37 strains were resistant to three or more antibiotics. There was a statistically significant relation between biofilm formation and multidrug resistance (against three or more antibiotics,p<0.001). In nondiabetic patients, $15(71 \%)$ isolates were non adherent or weakly adherent, and 2(10\%) were strongly adherent biofilm positive.

Conclusion

In conclusion, bacterial conjunctival flora of patients with diabetes is likely to produce biofilm. Biofilm formation is associated with multidrug rsistance in patients with diabetes.
\end{abstract}

Keywords: Diabetes; biofilm; Staphylococcus spp;; antibiotic resistance; ocular surface

\section{Introduction}

The ocular surface has a number of defense mechanisms for the prevention of ocular infections. Protein constituents in tears (lysozyme, immunoglobulins, lactoferrin) as well as bacterial flora of the ocular surface have a major role in restricting the growth of bacterial species ${ }^{1}$. However, sources of many ocular infections, especially post-operative ones, are ocular flora members. For example, coagulase negative Staphylococci (CoNS) are by far the most isolated microorganisms from post-operative endophthalmitis ${ }^{2-4}$. Diseases that break down immunity such as diabetes mellitus (DM), acquired immunodeficiency syndrome (AIDS) and/or other systemic diseases may contribute to the occurrence of infections. In particular, DM affects cell mediated immunity and also lacrimal secretions ${ }^{5,6}$. Under such circumstances, flora gain virulence, which can include biofilm production properties or antibiotic resistance. One of the main virulence factors for Staphylococci spp. predominantly found in the ocular flora is biofilm production. Biofilms, whose syntheses are controlled by the intercellular adhesion (ica) genes, are non-homogeneous collections of bacteria which are bound together by an excreted matrix ${ }^{7-9}$. The enzyme $\mathrm{N}$-acetylglucosaminyltransferase synthesizes polysaccharide intercellular adhesion (PIA), fromUDP-N-acetylglucosamine in vitro that is encoded by the ica locus and by the coexpression of icaA with icaD genes? ${ }^{9}$ Biofilm formation of Staphylococci, which was isolated from infected eyes, has been reported previously ${ }^{10,11}$. However, to our knowledge, this study is the first to show biofilm formation and genetic analysis of biofilms of Staphylococcus spp. that are isolated from the healthy conjunctiva of patients with diabetes. In this study we investigated genotypic and phenotypic structures of biofilm which are produced by Staphylococcus spp. and the effect of biofilms on antibiotic susceptibility.

\section{Methods}

\section{Subjects}

This study is a retrospective study. Isolates in this study were 
obtained from previous studies which had been stored at - 80 C. Purification was done for this study. Eighty three isolates were obtained from 50 eyes of diabetic patients (24 female, 26 male; age range: 50-88 years) with at least 10 years duration of Type II DM and without any ocular infection or allergic symptoms, and also 21 isolates of 38 eyes of non-diabetic patients (19 female, 19 male; age range: 47-89 years). The study followed the principles of the Declaration of Helsinki. Sampling technique is explained elsewhere. ${ }^{12}$

\section{Bacterial identification}

The swabs obtained were inoculated on to mannitol salt, nutrient and blood agar plates. The incubation temperature and duration was $37^{\circ} \mathrm{C}$ and $24-48$ hours respectively. Growing colonies were inoculated using the same media one by one for purification. Isolates that had been obtained from plates were identified using conventional (Gram stain, catalase, oxidase, coagulase, and DNAase reaction) and molecular microbiological methods. The strains were further identified with VITEK II system (BioMerieux, Durham, NC, USA) according to the manual of manufacturer. The identification ability of these systems depends upon the number and diversity of bacteria in the databases.

DuPont Qualicon RiboPrinter ${ }^{\circledR}$ Microbial Characterization System (Oxoid, Hampshire, UK) and the standard EcoRI DNA preparation kit were used for Automated EcoRI Ribotyping according to the manufacturer's guides. The reference DuPont identification database DUP2003 was used for comparison of ribotype profiles. Each isolate was identified when there was a similarity $\geq 0.85$ between the corresponding pattern and the matching pattern of the DuPont identification Library. The ribogroups were made up of the isolates automatically by the RiboPrinter ${ }^{\mathrm{TM}}$ according to the the matching similarity of the ribotype patterns. The generated Finger Printing II software was used to analyse Riboprinter ${ }^{\circledR}$ and a dendrogram was created according to Unweighted Pair Group Method using arithmetic Averages (UPGMA) and Pearson correlation coefficients (optimization 1.56\%). Strains were stored in $15 \%$ glycerol and at $-80^{\circ} \mathrm{C}$. Working cultures were stored at $5 \mathrm{C}$ and transferred periodically.

\section{Biofilm formation}

Congo red agar (CRA) method: Biofilm formation in Staphylococcus strains was detected by growth on congo red agar (CRA) plates ${ }^{13}$. CRA plates that were inoculated were incubated for 24 hours at $37^{\circ} \mathrm{C}$. Then, they were stored at room temperature for 48 hours. Appearance of the rough black colonies indicates the slime producing strains of coagulase-negative Staphylococcus. Microtiter plate assay (MPA): A microtiter assay was used to detect biofilm production as previously described ${ }^{14}$. Staphylococcus strains were added into $10 \mathrm{ml}$ of tryptic soy broth (TSB) with $0.25 \%$ glucose. Then incubated for 24 hours at $37^{\circ} \mathrm{C}$.Cultures were diluted at 1:100, diluted cultures $(200 \mu \mathrm{l})$ per well were distributed into 96 well polystyrene microtiter plates and under aerobic conditions incubation was done at $37^{\circ} \mathrm{C}$ for 24 hours. After incubation, they were washed with sterile phosphate buffered solution (PBS) twice, fixed in ethanol $(99 \%)$ for 15 minutes, and washed again with PBS. Then $200 \mu \mathrm{l}$ of $2 \%$ crystal violet per well was used to stain the plates for 5 minutes. Excess stain was washed out and the plates were left to dry. The bond between the dye and the adherent cells was broken with the use of $160 \mathrm{ml}$ of $33 \%$ $(\mathrm{v} / \mathrm{v})$ glacial acetic acid. The optic densitometry (OD) was measured at $570 \mathrm{~nm}$ by using an automated microplate reader. The reading was done before glacial acetic acid addition, as in standard microtiter plate, and after glacial acetic acid addition ${ }^{14}$. Classification of the results provided by the microtiter-plate test according to Christensen et al has three categories ${ }^{15}$. However Stepeanovic et al. modified the classification ${ }^{14}$. Strains were classified as follows: OD $\leq$ $\mathrm{OD}_{\mathrm{c}}$ non-adherent, $\mathrm{OD}<\mathrm{OD} \leq 2 \mathrm{xOD}_{\mathrm{c}}$ weakly adherent, $2 \mathrm{xOD}_{\mathrm{c}}<\mathrm{OD} \leq 4 \mathrm{xOD}_{\mathrm{c}}$ moderately adherent, $4 \mathrm{xOD}_{\mathrm{c}}<$ OD strongly adherent.

All tests were performed thrice and the mean of the results was calculated.

\section{Scanning electron microscopy analysis}

Scanning electron microscopy (SEM) (GeminiSem, Zeiss, Germany) biofilm specimens were prepared by fixation, staining, drying, and conductivity coating prior to imaging under high vacuum ${ }^{16}$. Firstly, bacteria were harvested and fixed in $2.5 \%$ glutaraldehyde in $0.1 \mathrm{M}$ cacodylate buffer for 2 hours at room temperature, post fixed in 1\% OsO4 (Osmium tetroxide) for 1 hour. Then bacteria were dehydrated in a series of ethyl alcohol (30, 50, 70, 90 and $100 \%$ ), with each for 15 minutes. Samples were incubated in $100 \%$ ethanol two times for 20 minutes. $\mathrm{CO}_{2}$ was used to dry them to a critical point. After that, according to standard procedures, they were prepared by sputtering gold film on them. Specimens were investigated with a Zeiss Ultra 50 Scanning electron microscope (SEM) operated at $5 \mathrm{kV}$ accelerating tension.

\section{Antibiotic sensitivity test}

Antibiotic sensitivity profile of the CoNS against antibiotics, which are commonly used as eye drops, were assessed by the disc diffusion method with respect to the guidelines of Clinical Laboratory Standards Institute ${ }^{17}$. Discs contained the following antibacterial agents: gatifloxacin (5 $\mu \mathrm{g})$, cefuroxime $(30 \mu \mathrm{g})$, ceftazidime $(30 \mu \mathrm{g})$, vancomycin $(30 \mu \mathrm{g})$, gentamicin $(10 \mu \mathrm{g})$, amikacin $(30 \mu \mathrm{g})$, ciprofloxacin $(5 \mu \mathrm{g})$, lomefloxacin $(10 \mu \mathrm{g})$, moxifloxacin $(5 \mu \mathrm{g})$, and methicillin $(5 \mu \mathrm{g})$.

\section{Detection of icaA, icaD, and bap genes encoding for biofilm using PCR}

Firstly, bacterial lysates were prepared and DNA was extracted. After PCR-amplification was achieved , examination by electrophoresis on agarose gel was done as described by Arciola et $\mathrm{al}^{18}$. Genomic DNA was extracted using Fermentas Gene JET ${ }^{T M}$ Genomic DNA purification kit (Thermo Fisher Scientific, Waltham, MA, USA) based on manufacturer recommendations. For detection of genes regarding biofilm formation, gene specific primers were used for PCR amplification of DNA. The primer sequences and PCR length are shown in Table 1. The reaction volume was $25 \mu \mathrm{l}$ that contained $10 \mathrm{X}$ TaqBuffer (+KCl, $-\mathrm{MgCl}_{2}$ ), $25 \mathrm{mM} \mathrm{MgCl} 2,2.5 \mathrm{mM}$ dNTP mix, 2.5 $\mathrm{mM}$ forward primer, $2.5 \mathrm{mM}$ reverse primer, Taq DNA polymerase $(5 \mathrm{u} / \mu \mathrm{l})$, nuclease- free distilled water, and template DNA. The PCR conditions for icaA and icaD 
were the following: 5 minute initial denaturation at $94^{\circ} \mathrm{C}$ ; 35 cycles of $94^{\circ} \mathrm{C}$ for $30 \mathrm{~s}, 55^{\circ} \mathrm{C}$ for $30 \mathrm{~s}$, and $72^{\circ} \mathrm{C}$ for $60 \mathrm{~s}$; and a five minute final extension at $72^{\circ} \mathrm{C}^{19}$. PCR conditions for the bap gene were $94^{\circ} \mathrm{C}$ for 5 min; 35 cycles of $94^{\circ} \mathrm{C}$ for $30 \mathrm{~s}, 42^{\circ} \mathrm{C}$ for $30 \mathrm{~s}$, and $72^{\circ} \mathrm{C}$ for $60 \mathrm{~s}$; and a five minute final extension at $72^{\circ} \mathrm{C}^{20}$.

Amplification products were analyzed using 1\% agarose gel electrophoresis. A further nucleotide sequence of the amplicon for bap gene was determined by sequencing. Amplicon that was purified from gel (Promega Wizard ${ }^{\circ}$ GelPCR Clean Up System, Promega BioSciences, LLC. San Luis Obispo, CA, USA) was sequenced by using DNA Beckman Coulter CEQ8000 Quick Start sequencing kit (Beckman Coulter, Fullerton, CA, USA). The data obtained from this sequencing procedure was compared with NCBI (National Center for Biotechnology Information) database by BLAST programme. Our sequencing data showed $92 \%$ similarity with Staphylococcus epidermidis biofilm-associated protein (bap) gene, complete cds (GenBank Accession Number DQ008306.1).

\section{Statistical analysis}

For statistical analysis, the Statistical Package for Social Sciences version 17 (IBM, Chicago, USA) statistical programme was used. Pearson Chi-square was performed to compare qualitative data. In order to assess the relation between the parameters, Pearson correlation analysis was performed $. \mathrm{P}<0.01$ and $\mathrm{p}<0.05$ were considered statistically significant .

\section{Results}

In diabetic patients, 83 conjounctival strains were isolated from 50 eyes, and 21 conjunctival strains were isolated from 38 eyes of non-diabetic subjects. The isolates were presumptively identified as Staphylococcus spp. According to conventional tests, isolates of diabetic patients were members of the species Staphylococcus epidermidis, Staphylococcus aureus, Staphylococcus warneri, Staphylococcus lugdunensis, Staphylococcus hominis, and Staphylococcus haemolyticus. Fig. 1 shows the RiboPrinter ${ }^{\circledR}$ Microbial Characterization System (Dupont Qualicon) results. S. epidermidis, S. aureus, S. warneri, S. lugdunensis, $S$. hominis, and $S$. haemolyticus were detected with the RiboPrinter ${ }^{\circledR}$ system. Although these genotypic identification results were almost concordant with those of VITEC II results, they were detected as $S$. epidermidis in 38, $S$. aureus in $8, S$. warneri in 19 , and other coagulase negative staphylococcus in the remaining 18 isolates.

S. epidermidis were dominant among the isolates obtained from the conjunctiva of healthy patients with diabetes (Fig 2). From 17 eyes, $38 \mathrm{~S}$. epidermidis conjunctival strains were isolated.

It was observed that $25(30 \%)$ out of 83 isolates were weakly positive, $20(24 \%)$ were moderately positive, and 25 $(30 \%)$ were strongly positive, with the remaining $13(16 \%)$ isolates biofilm negative with at least one of the methods used for detection of biofilm formation (Fig. 3).

According to conventional tests and the RiboPrinter ${ }^{\circledR}$ Microbial Characterization System, isolates of non-diabetic subjects were members of the species $S$. epidermidis, S. aureus,

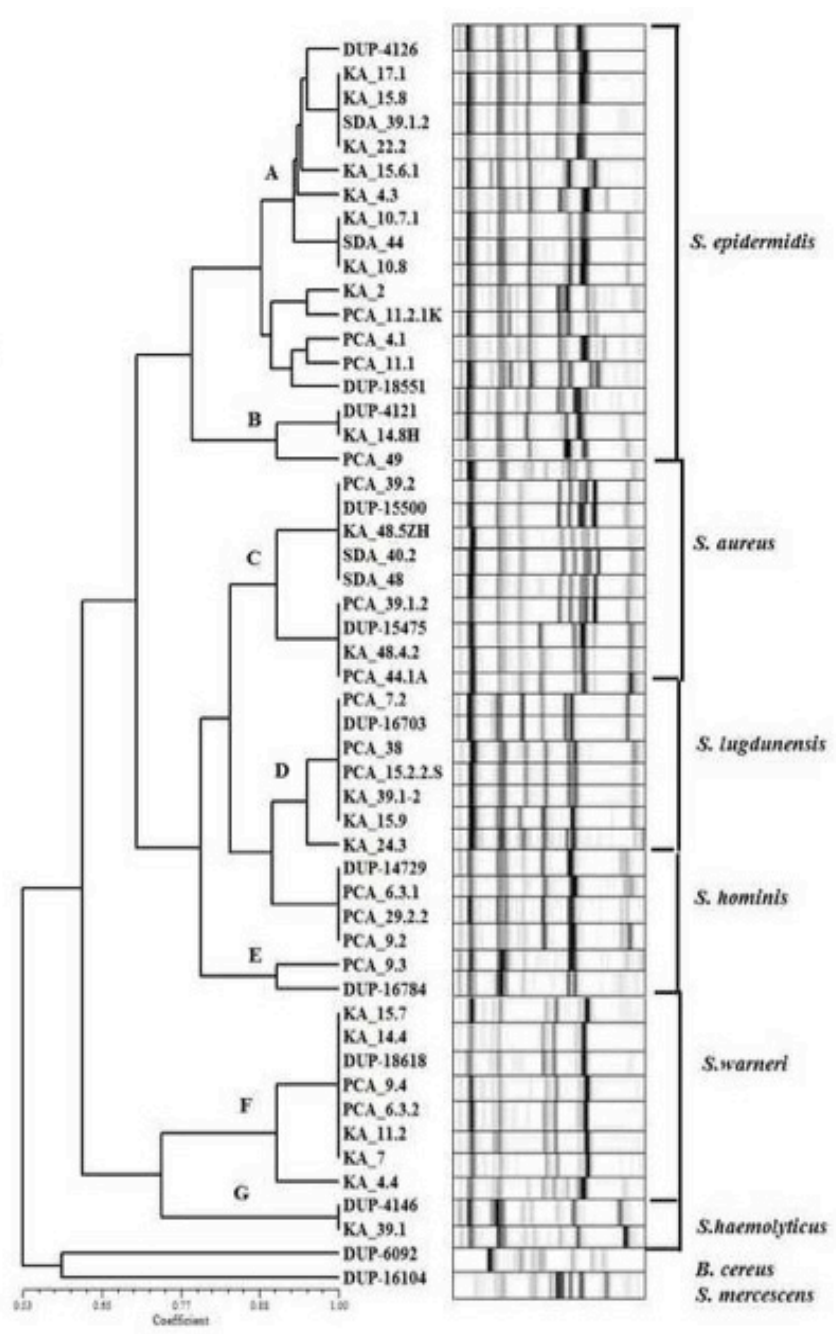

Fig. 1: Riboprinter ${ }^{\circledR}$ microbial characterization system (DupontQualıcon) results in diabetic patients showing ribotyping profiles of the isolates $S$. epidermidis, $S$. aureus, S. warneri, S. lugdunensis, S. hominis and S. baemolyticus

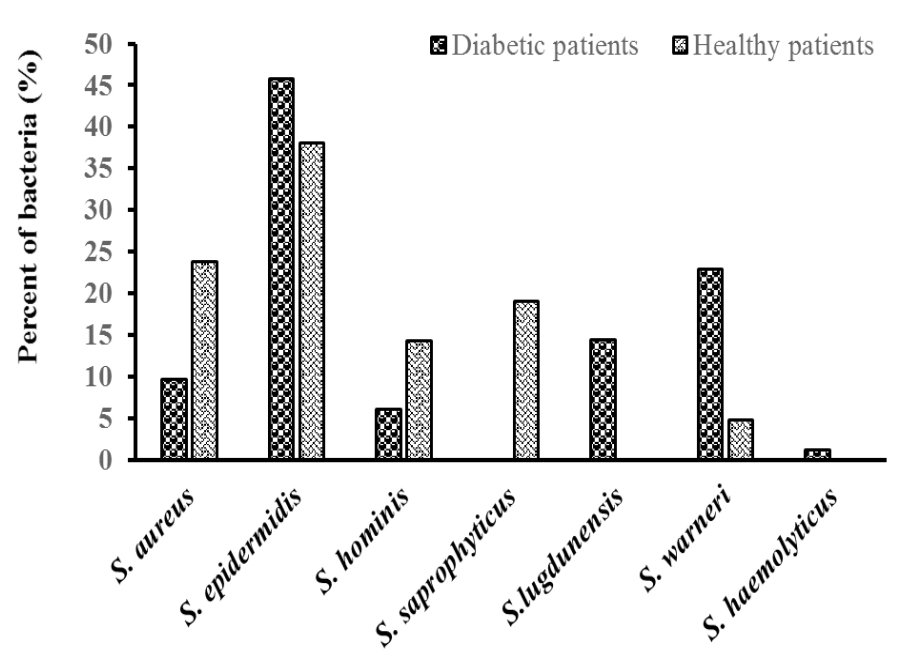

Fig. 2: Isolation rate of strains in healthy and type II diabetic cohorts

S. warneri, S. hominis, and S. saprophyticus (Fig. 2) . Fifteen (71\%) out of 21 isolates were non-adherent or weakly adherent, 4 $(19 \%)$ were moderately adherent, and $2(10 \%)$ were strongly adherent biofilm positives (Fig. 3). 


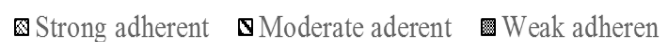
No adheren

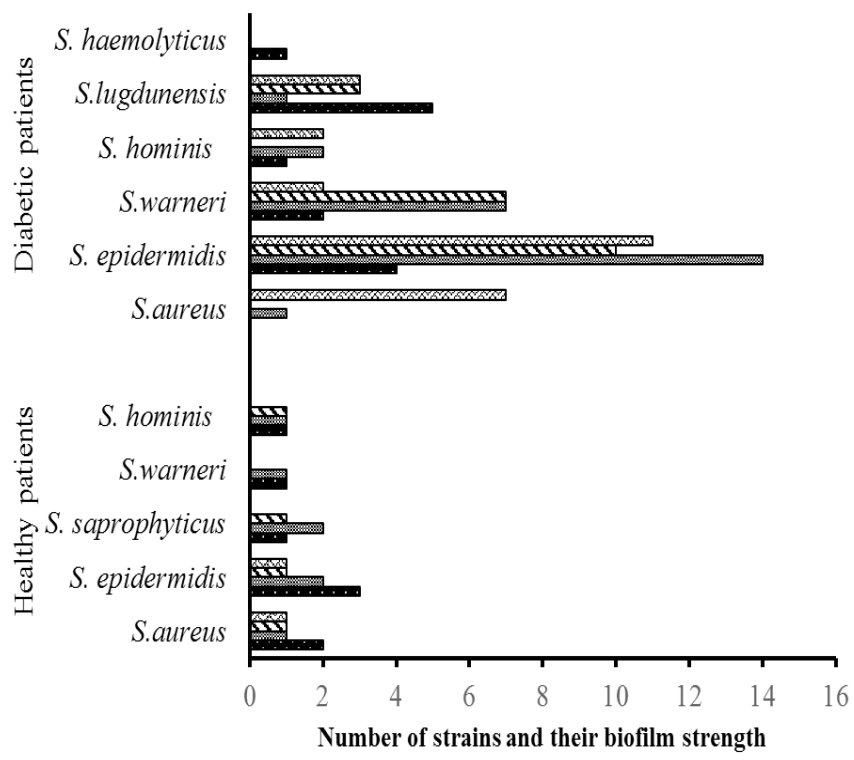

Fig. 3: Number of strains and their biofilm strength with at least one of the methods in healthy and type II diabetic cohorts:
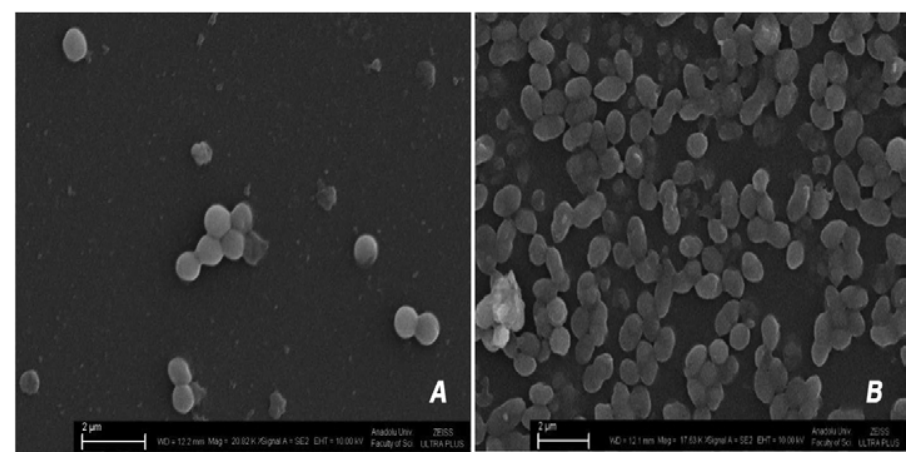

Fig. 4: SEM microphotographs; A) A weak (S. epidermidis KA 14.5) biofilm producer strains, B) A strong (S. epidermidis KA 15.8 ) biofilm producer strains from diabetic patients

The rate of strong biofilm formation of $S$. aureus as the prominent pathogenic microorganism of the flora in the non-diabetic group was $20 \%$, whereas the rate in the diabetic group was $88 \%$. The examples of weak and strong biofilm formation by Sepidermidis colonies of diabetic patients are shown in Fig 4A and 4B in SEM microphotographs. Seven isolates of $S$. aureus, 11 isolates of $S$. epidermidis, 2 isolates of $S$. warneri, 3 isolates of $S$. hominis, and 2 isolates of $S$. lugdunensis from diabetics were found to be strong biofilm producers (Fig. 3).

The antibiogram study revealed that 5 isolates of $S$. aureus, 19 isolates of S. epidermidis, 15 isolates of S. warneri, and 9 isolates of $S$. lugdunensis in diabetic patients were resistant to methicillin (Fig. 5). Out of 83 Staphylococcus isolates, 37 were cefuroxime resistant, 18 were ciprofloxacin resistant, 9 were amikacin resistant, 11 were vancomycin resistant, 12 were gatifloxacin resistant, 16 were lomefloxacin resistant, and 18 were moxifloxacin resistant. There was no isolate resistance to gentamicin. In total, 37 strains (45\%) were resistant to three or more antibiotics. Drug resistance against 6 or more antibiotics was detected in $11(13 \%)$ isolates, against 7 or more in $3(4 \%)$, and against 8 antibiotics in $1(1 \%)$ (Fig. 5). The relation between biofilm formation and multidrug resistance (against three or more antibiotics) was statistically significant $(\mathrm{p}<0.001)$. In the biofilm positive coagulase negative staphylococcus strains, the resistance rate was high to methicillin (67\%), cefuroxime $(37 \%)$, and ceftazidime $(41 \%)$, whereas the resistance rate was low against gentamicin (4\%). I $\mathrm{n}$ the biofilm negative S. epidermidis strains, the resistance rate was high to ciprofloxacin $(14 \%)$ and the resistance rate was $10 \mathrm{w}$ to methicillin (3\%). Biofilm producing S. epidermidis strains showed a significantly increased methicillin resistance (63\%). Methicillin resistance was $50 \%$ in biofim-positive and $44 \%$ in biofilm-negative strains (Fig. 5). In non-diabetic subjects, 6 isolates were cefuroxime resistant, 8 were ceftazidime resistant, 5 were ciprofloxacin resistant, 2 were vancomycin resistant, 1 was gatifloxacin resistant, 3 were lomefloxacin resistant, and 4 were moxifloxacin resistant. There was no resistance to both gentamicin and amikacin. Only 1 isolate had resistance against $6(5 \%)$ antibiotics. No resistance was detected against 7 antibiotics or more (Fig. 5).

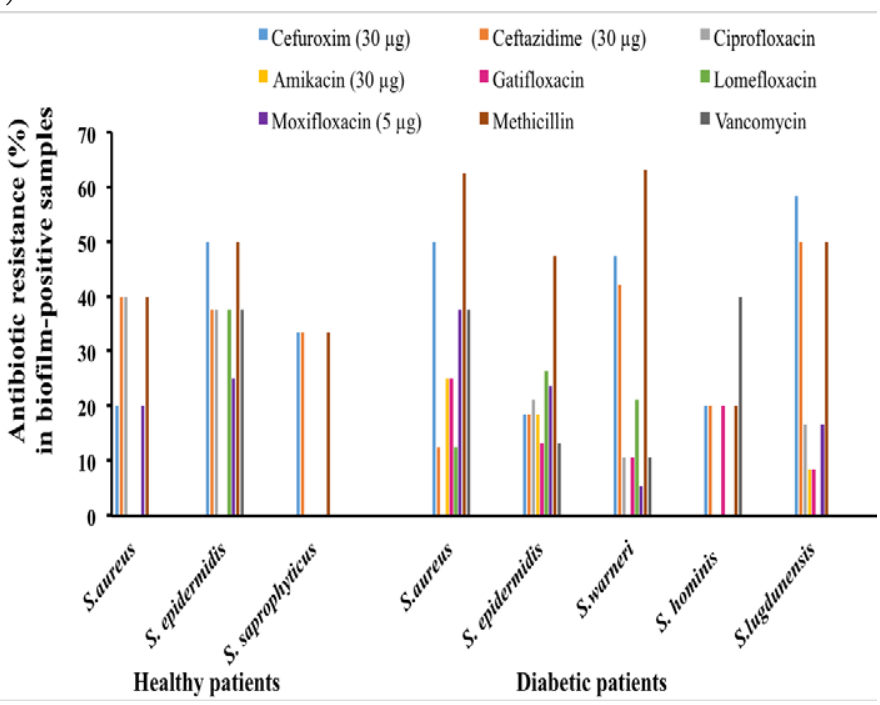

Fig. 5: Antimicrobial resistance to antibiotics of biofilm-positive Staphyloccocus spp. strains in healthy and type II diabetic cohorts

All isolated strains from diabetic patients were positive for $i c a A$ and icaD. The biofilm-producing and non-producing Staphylococcus spp. had both genes, giving a 188-bp band for the icaA gene and a 198-bp band for the icaD gene (Fig. $6 \mathrm{~A}$ and B). The molecular weight marker kit was used to determine the size of standard bands, then the image analyzer system designated the expected lengths to the bands that were obtained by amplification of the extracted DNA.

DNA extracted from 8 S. aureus, 18 S. warneri, 5 S. hominis, 12 S. lugdunensis, 1 S. haemolyticus, and 39 S. epidermidis isolates were tested for icaA, icaD detection, and the bap gene by PCR using gene-specific primers (Fig $6 \mathrm{C}$ ). All isolates had ica $A$ and icaD positivity, and one of the tested isolates was found to be bap positive. Sequencing was done for the bap gene. Sequencing of this amplicon showed $92 \%$ similarity with $S$. epidermidis biofilm-associated protein (bap) gene, complete cds (GenBank Accession Number DQ008306.1).

All of the isolates of non-diabetic subjects were icaD and icaA positive. No bap positivity was detected. 

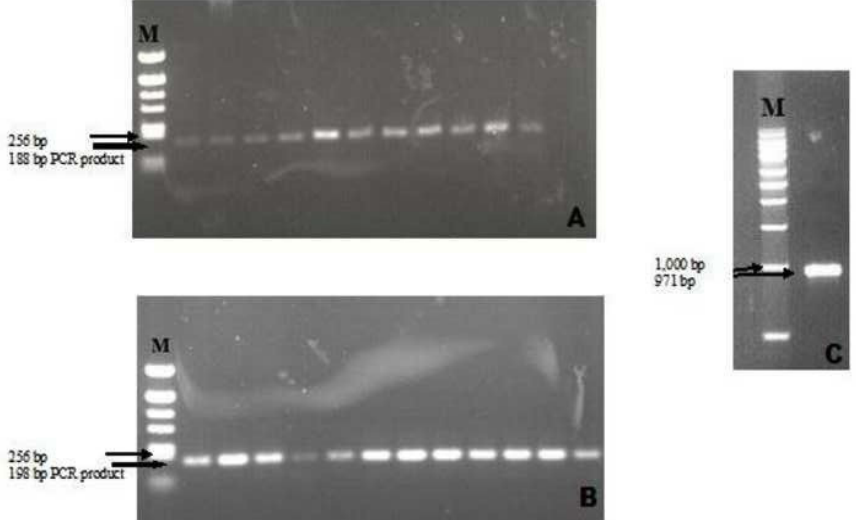

Fig. 6: PCR amplified product of (A) icaA gene. M; pBR322 DNA/ AluI Marker (Fermentas) (B) icaD gene. M; pBR322 DNA/AluI Marker (Fermentas) and (C) bap gene. M; DirectLoad 1 kb DNA Ladder (Sigma-Aldrich).

\section{Discussion}

Coagulase negative staphylococci are types of flora found in the eyelids, meibomian glands, and especially on the ocular surface. It has been shown that these bacteria enter the eye during and after intraocular surgery, which may cause endophthalmitis, a devastating complication of operations ${ }^{4,21-23}$. However, this complication is rare because of the equilibrium between host defense, bacterial virulence, and antibiotic resistance. Recent studies show that one of the major virulence factors for bacteria, especially for staphylococci, is biofilm production. Microorganisms, which produce biofilms are also more prone to develop resistance to antibiotics ${ }^{7,24,25}$.

The rate of strong biofilm formation in diabetic patients was $30 \%$, whereas the rate is $10 \%$ in non-diabetic subjects. On the one hand, we found that, in diabetics, the rate of strong biofilm formation of $S$. aureus as the prominent pathogenic microorganism was $88 \%$ whereas it was $20 \%$ in the control group. This study may suggest that bacteria from the ocular surface in patients with diabetes are likely to produce biofilm. Moreover, non-biofilm producer strains are more susceptible to antibiotics than the biofilm producers.

In previous studies, the rates for biofilm production of S. epidermidis were $34-74 \%$ in infected eyes and $18-46 \%$ in healthy conjunctivas according to CRA methods ${ }^{10,11,26,27}$. In this study, the biofilm production rate of all Staphylococcus and all CoNS are $77 \%$ and $74 \%$, respectively, according to CRA methods and $79 \%$ in diabetics. Our rate is higher than the rate found in previous studies in which healthy eyes were evaluated and similar to those with ocular infections, though our samples were taken from healthy eyes. This may be attributed to the presence of diabetes in the cohort, probably facilitating the rate of biofilm production.

Studies concerning biofilm production from healthy eyes are limited in literature. Suzuki et al. reported that their biofilm production rate for S. epidermidis was $46 \%$ and they noticed that all black colonies in the CRA were ica $A$ positive ${ }^{26}$. Verdayes et al. also reported a lower rate $(18 \%)$ for biofilm production; however their rates for ica $\mathrm{A}$ positivity for biofilm positive isolates were $88 \%$ and icaD positivity were $100 \%{ }^{27}$. In this study, both $i c a A$ and $i c a D$ positivity rates of biofilm plus strains are $100 \%$. In addition to the ica genes, we investigated isolates for the bap gene, which we detected in one isolate. Also in non-diabetics, the rates for $i c a A$ and icaD positivity in all isolates is $100 \%$ but no positivity for bap is detected. Due to the small sample size of control subjects in this study, it was not feasible to compare the results of diabetic patients with the control subjects statistically. Therefore, we only presented the findings of the healthy control subjects.

We noticed a correlation between biofilm formation capacity and antibiotic resistance. We found there was no vancomycin resistance in non-biofilm producer strains; however, vancomycin resistance was found in 12 of the biofilm producer strains. For fluoroquinolones, which are frequently used as eye drops, resistance was also similar. In diabetics, the number of resistant strains in non-biofilm producers for ciprofloxacin was 5, lomefloxacin was 2, moxifloxacin was 1 , and gatifloxacin was 0 . These numbers for isolates in biofilm producer strains were $12,15,15$, and 12 , respectively. In non-diabetic subjects, similar to the nonbiofilm producer strains of diabetic patients, the number of resistant strains in biofilm producer strains for ciprofloxacin was 5 , for lomefloxacin it was 3 , for moxifloxacin it was 4 , and for gatifloxacin it was 1 .

We found that biofilm producing strains are all susceptible to gentamicin. Multidrug resistance was found to be related to biofilm formation. Antibiotic susceptibility rates of biofilm producing strains from patients with diabetes have not been previously published. Catalanotti et al. reported that biofilm producing microorganisms, which were isolated from the conjunctiva of soft contact lens users, had higher antibiotic resistance than non-biofilm producers $^{10}$. They noticed that all S. epidermidis were susceptible to gentamicin, netilmicin, ofloxacin, neomycin, and kanamycin ${ }^{10}$. Alabiad et al. showed the fluoroquinolone resistance of conjunctival cultures to be 33\% from patients who had undergone intravitreal injection ${ }^{28}$. Blanco et al. reported that staphylococci isolates from chronic conjunctivitis were highly susceptible to vancomycin and moxifloxacin ${ }^{29}$. Methicillin sensitive S. epidermidis had low susceptibility to ciprofloxacin and erythromycin. Methicillin resistant $S$. epidermidis was only susceptible to moxifloxacin and vancomycin ${ }^{29}$. However, these studies did not mention the biofilm states of the isolates and whether these isolates were obtained from patients with diabetes or not. The relationship between biofilm formation and multidrug resistance has been reported previously ${ }^{26,31,32}$.

We have isolated non-biofilm producing strains which were $i c a A$ and icaD positive. Similar findings were reported from Hou et al previously, and they noted that the bacterial strains required genetic capability for biofim production; it is not implied that the biofilms will certainly form ${ }^{11}$.

Diabetes Mellitus (DM) is a systemic disease which damages cell-mediated immunity. Because of diabetes, retinopathy may develop. DM may also cause cataract. Besides these diseases, DM may cause some changes on the ocular surface and tear film 6 . Thus, microbial flora of the ocular surface varies. There are studies on the ocular surface flora of diabetic patients, which have shown that culture positivity and CoNS rates are higher in patients with diabetes; and the flora of the conjunctiva in diabetic patients is different from non-diabetic patients ${ }^{33-35}$. However, to the best of our knowledge, biofilm capacity of the ocular surface bacteria of patients with diabetes has not been reported before. In order to reduce or inhibit biofilm production in diabetic patients, specific strategies have not been defined yet. During biofilm formation, the process of 
bacterial attachment may be affected by species of bacteria, the surface condition, environmental factors (presence of glucose, etc.), growth medium, and essential gene products ${ }^{36}$. Antibiotics inhibit biofilm formation in vitro when added into media at the same time as the microorganism, however the effect of antibiotics is limited on preformed biofilm ${ }^{37}$. On the one hand, any agent that can change the viscoelastic property of the biofilm, chelating agents (EDTA), and polyamines (norspermidine) is helpful in inhibiting biofilm formation ${ }^{38,39}$. Therefore, besides an adequate metabolic control of glucose in diabetic patients, any measure targeting one of these factors may be helpful in the future for controlling or inhibiting biofilm production.

In this study, we report the staphylococcal characteristics of the ocular flora. We found CoNS $(90 \%)$ as a dominant group of the staphylococcal flora, and the main member of this group is $S$. epidermidis (45\%). There are few studies about biofilm producing microorganisms that are isolated from patients' bodies with diabetes except the eyes. Podbielska et al. reported that $59 \%$ of $S$. aureus and $75 \%$ of S. epidermidis from feet of diabetic patients had produced biofilms. ${ }^{40}$ However, they did not mention the ica status of the isolates.

\section{Conclusion}

Bacterial conjunctival flora of patients with diabetes may be more likely to produce biofilms. Biofilm formation is associated with multidrug resistance. Further studies with larger control groups may improve our understanding of biofilm formation and properties in diabetic patients. Patients with a long duration of diabetes should be evaluated carefully before planned surgery. It should be kept in mind that antibiotic resistance patterns may be vital for the success of surgery.

\section{Conflicts of Interest}

All contributing authors declare no conflicts of interest.

\section{Acknowledgements}

This study was supported by "Anadolu University of Research Project Fund" (Project No: 1306F164)

\section{References}

1. McClellan KA. Mucosal defense of the outer eye. Surv Ophthalmol. 1997;42(3):233-46.

2. Callegan MC, Booth MC, Jett BD, Gilmore MS. Pathogenesis of gram-positive bacterial endophthalmitis. Infect Immun. 1999;67(7):3348-56.

3. Miller JJ, Scott IU, Flynn HW Jr, Smiddy WE, Newton J, Miller D. Acute-onset endophthalmitis after cataract surgery (2000-2004): incidence, clinical settings, and visual acuity outcomes after treatment. Am J Ophthalmol. 2005;139(6):983-7. doi: 10.1016/j. ajo.2005.01.025

4. Han DP, Wisniewski SR, Wilson LA, Barza M, Vine AK, Doft BH et al. Spectrum and susceptibilities of microbiologic isolates in the Endophthalmitis Vitrectomy Study. Am J Ophthalmol. 1996;122(1):1-17.

5. Chang FY, Shaio MF. Decreased cell-mediated immunity in patients with non-insulin-dependent diabetes mellitus. Diabetes Res Clin Pract. 1995;28(2):137-46.

6. Goebbels M. Tear secretion and tear film function in insulin dependent diabetics. Br J Ophthalmol. 2000;84(1):19-21. doi: 10.1136/ bjo.84.1.19

7. Zegans ME, Becker HI, Budzik J, O'Toole G. The role of bacterial biofilms in ocular infections. DNA Cell Biol. 2002;21(5-6):415-20. doi: $10.1089 / 10445490260099700$

8. Mack D, Haeder M, Siemssen N, Laufs R. Association of biofilm production of coagulase-negative staphylococci with expression of a specific polysaccharide intercellular adhesin. J Infect Dis. 1996;174(4):881-4.

9. Gerke C, Kraft A, Süssmuth R, Schweitzer O, Götz F. Characterization of the N-acetylglucosaminyltransferase activity involved in the biosynthesis of the Staphylococcus epidermidis polysaccharide intercellular adhesin. J Biol Chem. 1998;273(29):18586-93.

10. Catalanotti P, Lanza M, Del Prete A, Lucido M, Catania MR, Gallè F, et al. Slime-producing Staphylococcus epidermidis and S. aureus in acute bacterial conjunctivitis in soft contact lens wearers. New Microbiol. 2005;28(4):345-54.

11. Hou W, Sun X, Wang Z, Zhang Y. Biofilm-forming capacity of Staphylococcus epidermidis, Staphylococcus aureus, and Pseudomonas aeruginosa from ocular infections. Invest Ophthalmol Vis Sci. 2012;53(9):5624-31. doi: 10.1167/iovs.11-9114.

12. Kıvanç SA, Kıvanç M, Güllülü G. Automated ribotyping and antibiotic resistance determining of Bacillus spp from conjunctiva of diabetic patients. Iran J Basic Med Sci. 2014;17(2):138-44. doi: 10.22038/IJBMS.2014.2248.

13. Freeman DJ, Falkiner ER, Keane CT. New method for detecting slime production by coagulase negative Staphylococci. J Clin Pathol.1989;42(8):872-4.

14. Stepanovic S, Vukovic D, Dakic I, Savic B, Svabic-Vlahovic M. A modified microtiter-plate test for quantification of staphylococcal biofilm formation. J Microbiol Methods. 2000;40(2):175-9.

15. Christensen GD, Simpson WA, Younger JJ, Baddour LM, Barrett FF, Melton DM, et al. Adherence of coagulase- negative staphylococci to plastic tissue culture plates: a quantitative model for the adherence of staphylococci to medical devices. J Clin Microbiol. 1985;22(6):996-1006.

16. Priester JH, Horst AM, Van de Werfhorst LC, Saleta JL, Mertes LA, Holden PA. Enhanced visualization of microbial biofilms by staining andenvironmental scanning electron microscopy. J Microbiol Methods. 2007;68(3):577-87. doi: 10.1016/j.mimet.2006.10.018

17. Clinical and Laboratory Standards Institute. Performance standards for antimicrobial susceptibility testing; twenty-third informational supplement. Document M100-S23. Wayne, PA: CLSI; 2013.

18. Arciola CR, Baldassarri L, Montanaro L. Presence of icaA and icaD genes and slime production in a collection of staphylococcal strains from catheter-associated infections. J Clin Microbiol. 2001;39(6):2151-6. doi: 10.1128/JCM.39.6.2151-2156.2001

19. Szweda P, Schielmann M, Milewski S, Frankowska A, Jakubczak A. Biofilm production and presence of ica and bap genes in Staphylococcus aureus strains isolated from cows with mastitis in the eastern Poland. Pol J Microbiol. 2012;61(1):65-9.

20. Cucarella C, Tormo MA, Ubeda C, Trotonda MP, Monzón M, Peris $\mathrm{C}$, et al. Role of biofilm-associated protein bap in the pathogenesis of bovine Staphylococcus aureus. Infect Immun. 2004;72(4):217785 .

21Moshirfar M, Feiz V, Vitale AT, Wegelin JA, Basavanthappa S, Wolsey DH. Endophthalmitis after uncomplicated cataract surgery with the use of fourth-generation fluoroquinolones: a retrospective observational case series. Ophthalmology. 2007;114(4):686-91. doi: 10.1016/j.ophtha.2006.08.038

22. Speaker MG, Milch FA, Shah MK, Eisner W, Kreiswirth BN. Role of external bacterial flora in the pathogenesis of acute postoperative endophthalmitis. Ophthalmology. 1991;98(5):639-49.

23. Bausz M, Fodor E, Resch MD, Kristóf K. Bacterial contamination in the anterior chamber after povidone-iodine application and the effect of the lens implantation device. J Cataract Refract Surg. 
2006;32(10):1691-5. doi: 10.1016/j.jcrs.2006.05.019

24. Josephberg RG. Endophthalmitis: the latest in current management. Retina. 2006;26(6 Suppl):47-50. doi: 10.1097/01. iae.0000236457.08393.3f

25. Ng JQ, Morlet N, Pearman JW, Constable IJ, McAllister IL, Kennedy CJ, et al. Management and outcomes of postoperative endophthalmitis since the endophthalmitis vitrectomy study: the Endophthalmitis Population Study of Western Australia (EPSWA)'s fifth report. Ophthalmology. 2005;112(7):1199-206. doi: 10.1016/j. ophtha.2005.01.050

26. Suzuki T, Kawamura Y, Uno T, Ohashi Y, Ezaki T. Prevalence of Staphylococcus epidermidis strains with biofilmforming ability in isolates from conjunctiva and facial skin. Am J Ophthalmol. 2005 ;140(5):844-50. doi: 10.1016/j.ajo.2005.05.050

27.Juárez-Verdayes MA, Ramón-Peréz ML, Flores-Páez LA, Camarillo- Márquez O, Zenteno JC, Jan-Roblero J, et al. Staphylococcus epidermidis with the $\mathrm{icaA}^{-} / \mathrm{icaD}^{-} / \mathrm{IS}_{2} 56^{-}$genotype and protein or protein/extracellular-DNA biofilm is frequent in ocular infections. $\mathrm{J}$ Med Microbiol. 2013;62(Pt 10):1579-87. doi: 10.1099/jmm.0.0552100

28. Alabiad CR, Miller D, Schiffman JC, Davis JL. Antimicrobial resistance profiles of ocular and nasal flora in patients undergoing intravitreal injections. Am J Ophthalmol. 2011;152(6):999-1004. doi: 10.1016/j.ajo.2011.05.026

29. Blanco C, Núñez MX. Antibiotic susceptibility of staphylococci isolates from patients with chronic conjunctivitis: including associated factors and clinical evaluation. J Ocul Pharmacol Ther. 2013;29(9):803-8. doi: 10.1089/jop.2013.0040

30. Miller D, Flynn PM, Scott IU, Alfonso EC, Flynn HW Jr. In vitro fluoroquinolone resistance in staphylococcal endophthalmitis isolates. Arch Ophthalmol. 2006;124(4):479-83. doi: 10.1001/ archopht.124.4.479

31. Murugan K, Usha M, Malathi P, Al-Sohaibani AS, Chandrasekaran M. Biofilm forming multi drug resistant Staphylococcus spp. among patients with conjunctivitis. Pol J Microbiol. 2010;59(4):233-9.
32. Kıvanç SA, Kıvanç M, Gullulu G. Biofilm and gelatinase production, antibiotic resistance and incidence of enterococcus faecalis on conjunctival swabs of diabetic patients. Turkiye Klinikleri J Med Sci 2013;33(1):67-72. doi: 10.5336/medsci.2012-28313

33. Martins EN, Alvarenga LS, Höfling-Lima AL, Freitas D, ZoratYu MC, Farah ME, et al. Aerobic bacterial conjunctival flora in diabetic patients. Cornea. 2004;23(2):136-42.

34. Fernández-Rubio ME, Rebolledo-Lara L, Martinez-García M, Alarcón-Tomás M, Cortés-Valdés C. The conjunctival bacterial pattern of diabetics undergoing cataract surgery. Eye (Lond). 2010;24(5):82534. doi: $10.1038 /$ eye.2009.218

35. Suto C, Morinaga M, Yagi T, Tsuji C, Toshida H. Conjunctival sac bacterial flora isolated prior to cataract surgery. Infect Drug Resist. 2012;5:37-41. doi: 10.2147/IDR.S27937

36. Khalil MA, Sonbol FI. Investigation of biofilm formation on contact eye lenses caused by methicillin resistant Staphylococcus aureus. Niger J Clin Pract. 2014;17(6):776-84. doi: 10.4103/1119-3077.144398

37. Kivanc SA, Akova Budak B, Yildiz M, Kivanc M. The effect of the linezolid and the vancomycine on biofilm production that formed on two different acrylic hydrophobic intraocular lenses. Invest Ophthalmol Vis Sci. 2015;56 (7): 287.

38. Di Stefano A, D’Aurizio E, Trubiani O, Grande R, Di Campli E, Di Giulio M, et al. Viscoelastic properties of Staphylococcus aureus and Staphylococcus epidermidis mono-microbial biofilms. Microb Biotechnol. 2009;2(6):634-41. doi:10.1111/j.1751-7915.2009.00120.x

39. Ramón-Peréz ML, Díaz-Cedillo F, Contreras-Rodríguez A, Betanzos-Cabrera G, Peralta H, Rodríguez-Martínez S, et al. Different sensitivity levels to norspermidine on biofilm formation in clinical and commensal Staphylococcus epidermidis strains. Microb Pathog. 2015;79:8-16. doi : 10.1016/j.micpath.2014.12.004

40.Podbielska A, Galkowska H, Stelmach E, Mlynarczyk G, Olszewski WL. Slime production by Staphylococcus aureus and Staphylococcus epidermidis strains isolated from patients with diabetic foot ulcers. Arch Immunol Ther Exp (Warsz). 2010;58(4):321-4. doi: 10.1007/ s00005-010-0079-9. 